\title{
ANALISIS KEAUSAN KAMPAS REM PADA DISC BRAKE DENGAN VARIASI KECEPATAN
}

\author{
Ahmad Taufik, Darmanto dan Imam Syafa'at \\ Jurusan Teknik Mesin, Fakultas Teknik, Universitas Wahid Hasyim \\ Jl. Menoreh Tengah X/22, Sampangan Semarang 50236 \\ ${ }^{1}$ Email : ahmadtaufik.kiko@gmail.com
}

\begin{abstract}
ABSTRAK
Kampas rem merupakan salah satu komponen kendaraan bermotor yang berfungsi untuk memperlambat atau menghentikan laju kendaraan. Dalam konsep pengereman hal yang tidak dapat dihindarkan adalah sebuah keausan. Keausan terjadi apabila dua buah benda yang saling menekan dan saling bergesekan. Dalam penelitian ini, dilakukan untuk mengetahui pengaruh kecepatan terhadap volume keausan, koefisien keausan dan laju keausan kampas rem dengan menggunakan alat uji keausan kampas rem dengan variasi kecepatan $60 \mathrm{~km} / \mathrm{jam}, 80 \mathrm{~km} / \mathrm{jam}$ dan $100 \mathrm{~km} / \mathrm{jam}$ dengan beban pengereman $2 \mathrm{Kg}$. Durasi waktu pengujian yaitu 10, 15, 20, 25, 30, 35 menit. Hasil penelitian ini untuk volume keausan tertinggi dengan waktu 35 menit yaitu pada kecepatan $60 \mathrm{~km} / \mathrm{jam}$ sisi kampas A 38,07 $\mathrm{mm}^{3}$ dan sisi kampas B 30,45 $\mathrm{mm}^{3}$, sedangkan kecepatan $80 \mathrm{~km} / \mathrm{jam}$ sisi kampas A $64,13 \mathrm{~mm}^{3}$ dan sisi kampas B 56,10 $\mathrm{mm}^{3}$, pada kecepatan $100 \mathrm{~km} / \mathrm{jam}$ sisi kampas A 43,96 $\mathrm{mm}^{3}$ dan sisi kampas B 37,70 mm. Sedangkan nilai koefisien keausan kampas A pada kecepatan $60 \mathrm{~km} / \mathrm{jam}$ sisi kampas $A 8,21 \times 10^{-8} \mathrm{~mm}^{3} / \mathrm{N} . \mathrm{mm}$ dan sisi kampas $B 7,72 \times 10^{-8} \mathrm{~mm}^{3} / \mathrm{N} . \mathrm{mm}$, kecepatan $80 \mathrm{~km} / \mathrm{jam}$ sisi kampas A $1,13 \times 10^{-7} \mathrm{~mm}^{3} / \mathrm{N} . \mathrm{mm}$ dan sisi kampas $B 1,03 \times 10^{-7} \mathrm{~mm}^{3} / \mathrm{N} . \mathrm{mm}$ dan kecepatan $100 \mathrm{~km} / \mathrm{jam}$ $1,17 \times 10^{-7} \mathrm{~mm}^{3} / \mathrm{N} . \mathrm{mm}$ dan B $1,08 \times 10^{-7} \mathrm{~mm}^{3} / \mathrm{N} . \mathrm{mm}$. Laju keausan pada waktu 35 menit dengan

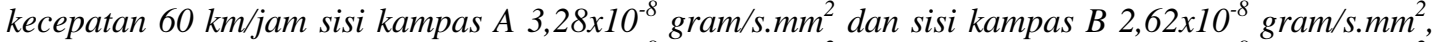

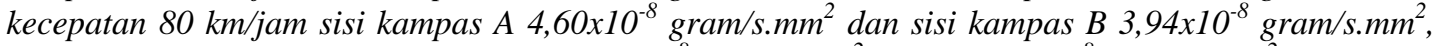

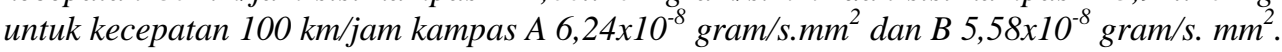

Kata Kunci : Kampas rem, Volume keausan, Koefisien keausan, Laju keausan.

\section{PENDAHULUAN}

Kampas rem adalah salah satu komponen kendaraan bermotor yang berfungsi untuk memperlambat atau menghentikan laju kendaraan bermotor. Pada saat kendaraan kecepatan tinggi kampas rem memiliki peranan yang sangat penting, sehingga menunjang keselamatan jiwa pengendara tergantung pada kualitas dari kampas rem (sasmito, 2012)

Dalam konsep pengereman hal yang tidak dapat dihindarkan adalah sebuah keausan. Keausan terjadi apabila dua buah benda yang saling menekan dan saling bergesekan. Keausan yang lebih besar terjadi pada bahan yang lebih lunak. Faktor-fakor yang mempengaruhi keausan adalah kecepatan, tekanan, kekerasan permukaan dan kekerasan bahan. Semakin besar kecepatan relatif benda yang bergesekan, maka material akan semakin mudah aus. Demikian pula semakin besar tekanan pada permukaan benda yang berkontak, material akan cepat aus, begitu pula sebaliknya. Pengikisan atau dalam kata lain disebut sebagai keausan. Keausan inilah yang menjadi salah satu faktor utama terhadap umur dari komponen-komponen dalam permesinan (Stachowiak, 2005).
Adapun tujuan dari penelitian ini yaitu:

1. Untuk mengetahui volume keausan pada kampas rem merk Indopart.

2. Untuk mengetahui koefisien keausan pada kampas rem merk Indopart.

3. Untuk mengetahui laju keausan kampas rem merk Indopart.

4. Untuk mengetahui hasil foto mikro kampas rem merk Indopart pada masing-masing kecepatan dengan waktu 35 menit.

\section{Gaya Gesek (Friction)}

Gaya gesek adalah gaya melawan arah gerak benda atau arah kecenderungan benda akan bergerak. Gaya gesek terjadi apabila dua benda saling melakukan kontak atau bersentuhan.

Gaya gesekan statis cenderung mempertahankan keadaan diam benda., dan gaya gesek kinetis yaitu cenderung mempertahankan gerak dari suatu benda.

a. Gaya gesekan statis

Gaya antar permukaan benda yang diam atau tidak ada gerak relatif antara satu benda dengan benda yang lainnya, bila benda ditarik dengan sebuah gaya dan benda tersebut belum bergerak berarti da gaya yang berlawanan arah dengan 
arah gerak benda tersebut. Gaya ini adalah gaya statis $\left(f_{s}\right)$ apabila gaya tarik diperbesar dan benda belum bergerak, berarti gaya gesekan statis $\left(f_{s}\right)$ bertambah besar sampai mencapai harga maksimum (fsmaks) sebanding dengan gaya normal $(\mathrm{N})$.

b. Gaya gesekan kinetis

Untuk menggerakan balok kayu diatas lantai dibutuhkan gaya untuk dapat mengatasi gaya gesekan statis $\left(f_{\mathrm{s}}\right)$ setelah bergerak gaya itu mempertahankan gerak benda dan digunakan untuk mengatasi gaya gesekan kinetisnya $\left(f_{\mathrm{k}}\right)$. Sehingga hanya diperlukan gaya yang lebih kecil dari gaya yang digunakan untuk mulai menggerakannya. Setelah gaya bergerak, gaya gesek statis $\left(f_{\mathrm{s}}\right)$ berkurang sedikit demi sedikit dan berubah menjadi gaya gesekan kinetis $\left(f_{\mathrm{k}}\right)$. Sehingga gaya kinetis selalu lebih kecil dari pada gaya gesekan statis maksimum (Sutrisno, 1986).

\section{Keausan (Wear)}

Keausan (wear) adalah hilangnya materi dari permukaan benda padat sebagai akibat dari adanya gerakan mekanik. Keausan umunya dianalogikan sebagai hilangnya materi akibat interaksi mekanik dua permukaan yang bergerak slidding dan dibebani. Ini merupakan fenomena normal yang terjadi jika dua benda permukaannya saling bergesekan, maka akan ada keausan atau perpindahan materi yang terjadi antara dua benda yang bergesekan (Blau, 1997).

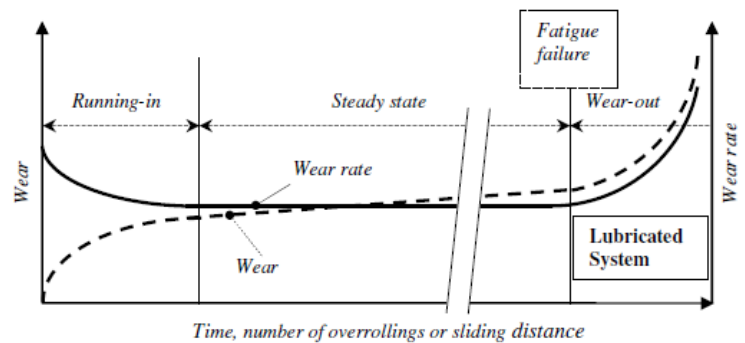

Gambar 1 Grafik tahapan keausan (Jamari, 2006)

Koefisien keausan dapat dihitung dengan rumus (Archard,1953)

$K_{D} \quad=\frac{V}{F N . S}$

Dimana:

$K_{D} \quad=$ koefisien keausan

$V \quad=$ volume material yang hilang $\left(\mathrm{mm}^{3}\right)$

$S \quad=\operatorname{jarak}(\mathrm{mm})$

$F_{N} \quad=$ beban norman $(\mathrm{N})$

Volume keausan dapat dihitung dengan menggunakan rumus (Lancaster dkk, 1997)
$V=\frac{m 1-m 2}{\rho}$

Dimana:

$V \quad=$ Volume keausan $\left(\mathrm{mm}^{3}\right)$

$m_{1} \quad=$ berat awal (gram)

$m_{2} \quad=$ berat setelah pengujian (gram)

$\rho=\quad=$ massa jenis material $\left(\mathrm{gram} / \mathrm{mm}^{3}\right)$

Laju keausan pada kampas rem dapat dihitung dengan rumus (Sukamto, 2012):

$N=\frac{m 1-m 2}{t . A}$

Dimana:

$m_{1} \quad=$ Berat mula benda uji (gram)

$m_{2} \quad=$ Berat pengausan $(\mathrm{gram})$

$N=$ Nilai laju keausan $\left(\right.$ gram/detik. $\left.\mathrm{mm}^{2}\right)$

$t \quad=$ Waktu pengausan (detik)

$A \quad=$ Luas penampang $\left(\mathrm{mm}^{2}\right)$

\section{METODE PENELITIAN}

Penelitian ini berisi tentang analisa keausan kampas rem cakram dengan variasi kecepatan dengan eksperimen menggunakan alat uji keausan kampas rem.

\section{Alat}

\section{Alat Uji Keausan Kampas Rem}

Alat uji keausan kampas rem adalah suatu alat yang digunakan untuk menguji keausan material kampas rem kendaraan bermotor agar di ketahui umur dari material kampas rem tersebut. Alat uji keausan rem menggunakan penggerak yaitu motor listrik untuk memutar disc, dan inverter sebagai pengatur kecepatan motor. Untuk mengatur putaran disc agar sesuai yang diinginkan maka motor dilengkapi dengan inverter. Hasil dari keausan material kampas yang di dapat digunakan sebagai acuan dalam penelitian ini. Adapun bagian dan fungsi dari alat uji keausan kampas rem seperti ditunjukan pada Tabel 1.

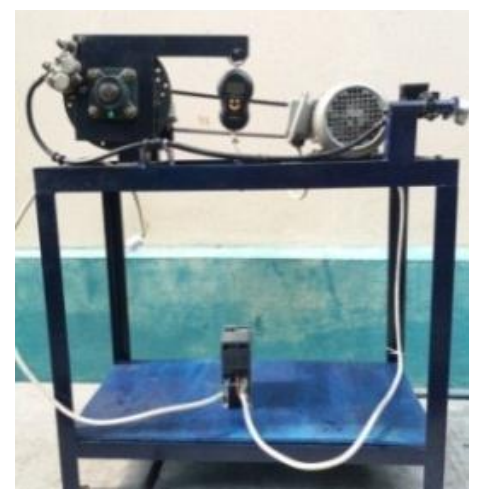

Gambar 2 Alat uji keausan rem 

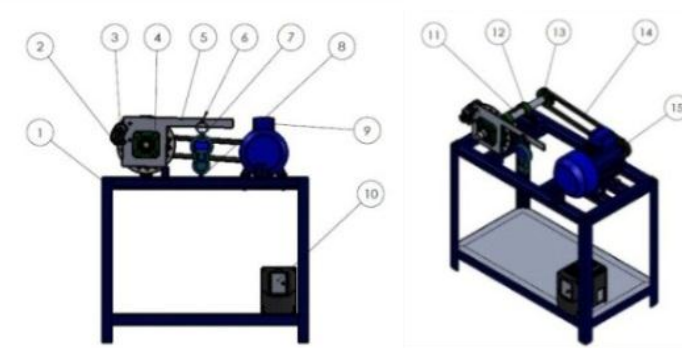

Gambar 3 Gambar teknik alat uji keausan kampas rem

Tabel 1 Bagian-bagian dan Fungsi Alat Uji Keausan Rem

\begin{tabular}{|c|c|c|}
\hline No. & Nama & Fungsi \\
\hline 1. & $\begin{array}{l}\text { Rangka atau } \\
\text { kontruksi }\end{array}$ & $\begin{array}{l}\text { Penopang komponen } \\
\text { alat uji }\end{array}$ \\
\hline 2. & Disc & $\begin{array}{l}\text { Untuk gaya gesek } \\
\text { antara disc dengan } \\
\text { kampas rem }\end{array}$ \\
\hline 3. & Kaliper & Untuk pemegang pad \\
\hline 4. & Bantalan & Penumpu poros \\
\hline 5. & Lengan beban & $\begin{array}{l}\text { Penghubung antara } \\
\text { beban dan disc }\end{array}$ \\
\hline 6. & Pengunci atas & $\begin{array}{l}\text { Sebagai pengunci } \\
\text { timbangan digital } \\
\text { bagian atas }\end{array}$ \\
\hline 7. & $\begin{array}{l}\text { Timbangan } \\
\text { digital }\end{array}$ & Untuk pengatur beban \\
\hline 8. & Pengunci bawah & $\begin{array}{l}\text { Untuk mengunci } \\
\text { timbangan digital } \\
\text { bagian bawah }\end{array}$ \\
\hline 9. & Motor listrik & $\begin{array}{l}\text { Memutar komponen } \\
\text { rangkaian rem }\end{array}$ \\
\hline 10. & Inverter & Pengatur kecepatan \\
\hline 11. & Poros & Sebagai pengerak disc \\
\hline 12. & Bantalan & Untuk penumpu poros \\
\hline 13. & Pully 1 & Meneruskan putaran \\
\hline 14. & $v$-belt & Menyalurkan putaran \\
\hline 15. & Pully 2 & $\begin{array}{l}\text { Meneruskan putaran } \\
\text { motor }\end{array}$ \\
\hline
\end{tabular}

\section{Bahan}

Adapun bahan-bahan yang digunakan pada saat pengujian adalah sebagai berikut:

1. Kampas rem cakram.

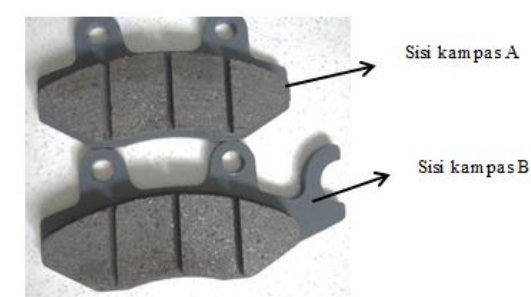

Gambar 4 Kampas rem

\section{Pengujian}

1. Benda yang diuji adalah 3 sampel kampas rem dengan merk Indopart, masing-masing sampel diberi kecepatan yang berbeda yaitu $60 \mathrm{~km} / \mathrm{jam}, 80 \mathrm{~km} / \mathrm{jam}, 100 \mathrm{~km} / \mathrm{jam}$.

2. Sebelum melakukan pengujian kampas rem terlebih dahulu ditimbang untuk mengetahui berat mula-mula (tanpa penampang besi) dari kampas rem baik sisi kampas A dan sisi kampas B.

3. Kampas rem diletakan pada kaliper.

4. Putaran motor diatur dengan inverter untuk mendapatkan variasi kecepatan yaitu 60 $\mathrm{km} / \mathrm{jam}, 80 \mathrm{~km} / \mathrm{jam}, 100 \mathrm{~km} / \mathrm{jam}$.

5. Meberikan pembebanan pengereman $2 \mathrm{Kg}$.

6. Pengambilan data dilakukan pengujian selama 10 menit pertama kemudian kampas rem ditimbang, selanjutnya dilakukan pengujian yang sama dengan waktu 15 menit, 20 menit, 25 menit, 30 menit dan 35 menit.

\section{HASIL DAN PEMBAHASAN}

Hasil pengujian keausan kampas rem menggunakan alat uji keausan rem dengan variasi kecepatan $60 \mathrm{~km} / \mathrm{jam}, 80 \mathrm{~km} / \mathrm{jam}$ dan $100 \mathrm{~km} / \mathrm{jam}$ dengan pembebanan $2 \mathrm{Kg}$ untuk setiap kecepatan pada waktu pengujian 10 menit, 15 menit, 20 menit, 25 menit, 30 menit, dan 35 menit

Data hasil penelitian yang telah dilakukan, diperoleh data yang menunjukan pengaruh variasi kecepatan terhadap volume keausan, koefisien keausan dan laju keausan.

1. Hasil volume keausan pada sisi kampas A dan sisi kampas B dengan kecepatan 60 $\mathrm{km} / \mathrm{jam}, 80 \mathrm{~km} / \mathrm{jam}$ dan $100 \mathrm{~km} / \mathrm{jam}$

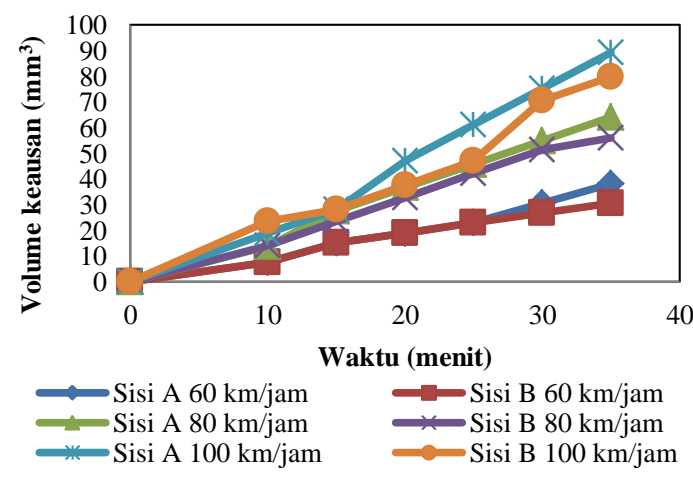

Gambar 5 Grafik hubungan volume keausan dengan waktu pada sisi kampas A dan sisi kampas B pada masing-masing kecepatan

Gambar 5 menunjukan volume keausan pada masing-masing kecepatan berbanding lurus dengan lama waktu pengujian. Hal ini menunjukkan bahwa semakin lama waktu pengujian kampas rem maka semakin besar 
pula volume keausan yang terjadi pada kampas rem tersebut. Hasil volume keausan dengan kecepatan $60 \mathrm{~km} / \mathrm{jam}$ pada waktu 10 menit sisi kampas A 7,61 $\mathrm{mm}^{3}$ dan sisi kampas B 7,61 $\mathrm{mm}^{3}$, pada waktu 35 menit volume keausan sisi kampas A 43,96 $\mathrm{mm}^{3}$ dan sisi kampas B 37,70 $\mathrm{mm}^{3}$. Volume keausan dengan kecepatan 80 $\mathrm{km} / \mathrm{jam}$ pada waktu 10 menit sisi kampas A $13,74 \mathrm{~mm}^{3}$ dan sisi kampas B 14,02 $\mathrm{mm}^{3}$, dengan waktu 35 menit sisi kampas A 64,13 $\mathrm{mm}^{3}$ dan sisi kampas B $56,10 \mathrm{~mm}^{3}$. Volume keausan kampas rem dengan kecepatan 100 $\mathrm{km} / \mathrm{jam}$ pada waktu 10 menit sisi kampas A $18,77 \mathrm{~mm}^{3}$ dan sisi kampas B 23,49 $\mathrm{mm}^{3}$, dengan waktu 35 menit sisi kampas A 89,16 $\mathrm{mm}^{3}$ dan sisi kampas B 79,88 $\mathrm{mm}^{3}$.

2. Hasil koevisien keausan pada sisi kampas A dan sisi kampas B dengan kecepatan 60 $\mathrm{km} / \mathrm{jam}, 80 \mathrm{~km} / \mathrm{jam}$ dan $100 \mathrm{~km} / \mathrm{jam}$.

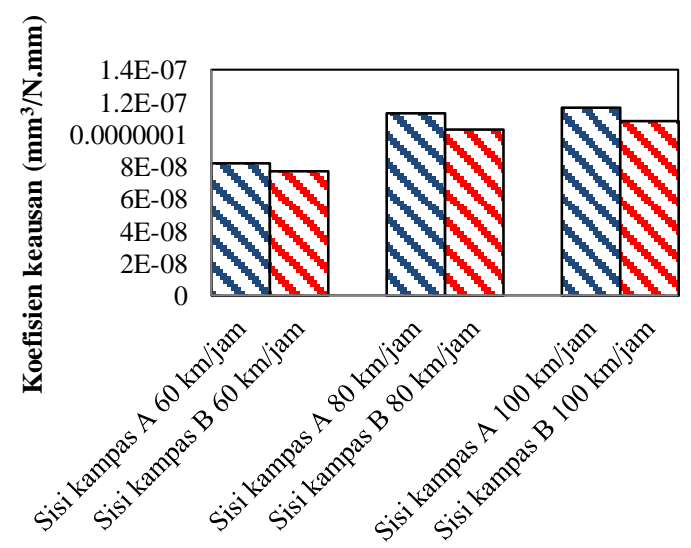

Gambar 6 Koefisien Keausan yang terjadi pada sisi kampas A dan sisi kampas B pada masingmasing kecepatan

Gambar 6 menunjukan bahwa semakin tinggi kecepatan yang diberikan maka semakin tinggi pula koefisien keausan. Hasil koefisien keausan dengan kecepatan $100 \mathrm{~km} / \mathrm{jam}$ pada sisi kampas A $1,17 \times 10^{-7} \mathrm{~mm}^{3} / \mathrm{N} . \mathrm{mm}$ dan Sisi kamaps B $1,08 \times 10^{-7} \quad \mathrm{~mm}^{3} / \mathrm{N} . \mathrm{mm}$. Hasil koefisien keausan dengan kecepatan $80 \mathrm{~km} / \mathrm{jam}$ pada sisi kampas A $1,13 \times 10^{-7} \mathrm{~mm}^{3} / \mathrm{N} \cdot \mathrm{mm}$ dan sisi kampas B $1,03 \times 10^{-7} \mathrm{~mm}^{3} / \mathrm{N} . \mathrm{mm}$, sedangkan koefisien keausan kecepatan $60 \mathrm{~km} / \mathrm{jam}$ sisi kampas A $8,21 \times 10^{-8} \mathrm{~mm}^{3} / \mathrm{N} . \mathrm{mm}$ dan sisi kampas B $7,72 \times 10^{-8} \mathrm{~mm}^{3} / \mathrm{N} . \mathrm{mm}$.

3. Hasil laju kausan sisi kampas A dan sisi kampas B pada masing-masing kecepatan

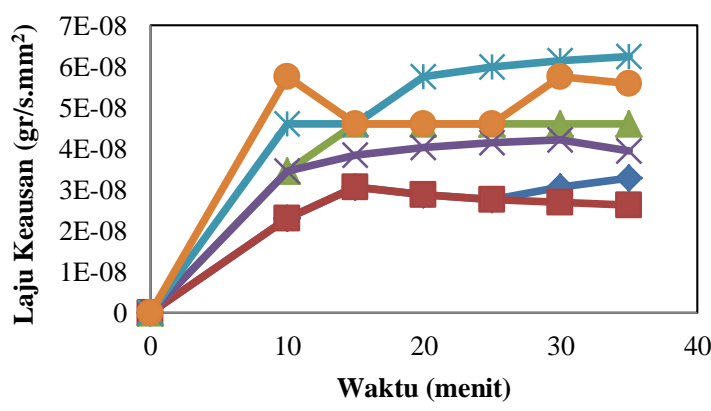

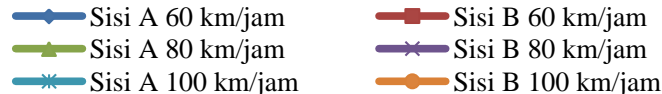

Gambar 7 Grafik laju keausan sisi kampas A dan sisi kampas B pada masing-masing kecepatan

Gambar 7 diawal pengujian meningkat seiring berjalannya waktu laju keausan yang terjadi cenderung stabil dan mengalami penurunan. Hasil laju keausan dengan kecepatan $60 \mathrm{~km} / \mathrm{jam}$ dengan waktu 10 menit sisi kampas A $2,30 \times 10^{-8}$ gram $/ \mathrm{s} . \mathrm{mm}^{2}$ dan sisi kampas B 2,30x $10^{-8} \mathrm{gram} / \mathrm{s} . \mathrm{mm}^{2}$, pada waktu 35 menit sisi kampas A $3,28 \times 10^{-8}$ gram $/ \mathrm{s} . \mathrm{mm}^{2}$

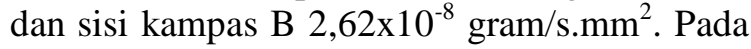
kecepatan $80 \mathrm{~km} / \mathrm{jam}$ dengan waktu 10 menit sisi kampas A $3,45 \times 10^{-8}$ gram $/ \mathrm{s}^{-\mathrm{mm}^{2}}$ dan sisi kampas B $3,45 \times 10^{-8}$ gram $/ \mathrm{s} . \mathrm{mm}^{2}$ dan pada waktu 35 menit sisi kampas A 4,60× $10^{-8}$ gram/s.mm ${ }^{2}$, sisi kampas B $3,94 \times 10^{-8}$ $\mathrm{gram} / \mathrm{s} . \mathrm{mm}^{2}$. Kecepatan $100 \mathrm{~km} / \mathrm{jam}$ dengan waktu 10 menit sisi kampas A 4,60× $10^{-8}$ gram $/ \mathrm{s} . \mathrm{mm}^{2}$, sisi kampas B $5,75 \times 10^{-8}$ $\mathrm{gram} / \mathrm{s} . \mathrm{mm}^{2}$, dengan waktu 35 menit sisi kampas A $6,34 \times 10^{-8}$ gram $/ \mathrm{s} . \mathrm{mm}^{2}$, sisi kampas B $5,58 \times 10^{-8} \mathrm{gram} / \mathrm{s} . \mathrm{mm}^{2}$.

4. Hasil foto mikro keausan kampas rem pada waktu 35 menit dengan pembesaran 100 kali.
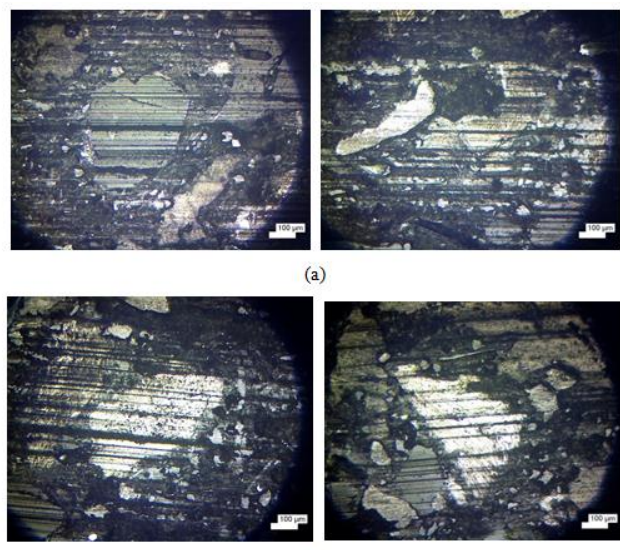


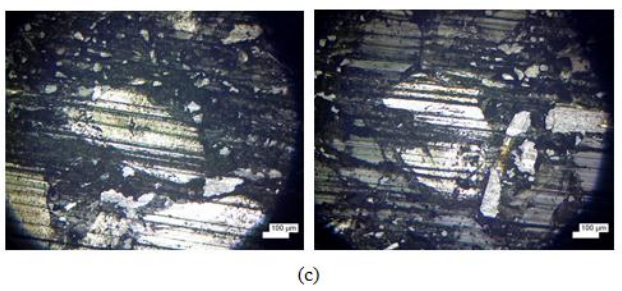

Gambar 8 Hasil foto mikro waktu pengujian 35 menit sisi kampas A dan B dengan perbesaran 100 kali untuk variasi kecepatan (a) $60 \mathrm{~km} / \mathrm{jam}$, (b) $80 \mathrm{~km} / \mathrm{jam}$, (c) $100 \mathrm{~km} / \mathrm{jam}$.

Dari hasil foto mikro pembesaran 100 kali, lama pengujian 35 menit dengan variasi kecepatan $60 \mathrm{~km} / \mathrm{jam}, 80 \mathrm{~km} / \mathrm{jam}$ dan 100 $\mathrm{km} / \mathrm{jam}$ dapat dilihat adanya pola goresan yang searah pada permukaan kampas rem. Kesamaan pola keausan yang terbentuk pada permukaan kampas rem hanya berupa keausan abrasi. Gambar (a) Pada saat kecepatan $60 \mathrm{~km} / \mathrm{jam}$ dapat dilihat pola goresan yang terlihat lebih banyak, namun dengan dimensi yang lebih sempit atau kecil. Jarak kerapatan pada goresan sangat dekat, adapun area keausan yang terjadi pada permukaan kampas rem terlihat lebih luas. Untuk kecepatan $80 \mathrm{~km} / \mathrm{jam}$ pola goresan yang terbentuk terlihat lebih lebar dari Gambar (a) untuk kedalaman goresan terlihat lebih dalam dari Gambar (a). Sedangkan pada Gambar (c) kecepatan $100 \mathrm{~km} / \mathrm{jam}$ terjadi pembentukan pola goresan yang lebih sedikit, begitu juga dengan kedalaman keausan yang terlihat jauh lebih dalam.

Apabila dibandingkan foto mikro permukaan kampas dari ketiga variasi kecepatan yang diberikan, maka dapat disimpulkan bahwa keausan yang terbentuk dari gesekan dengan metode abrasif. Dapat juga disimpulkan bahwa semakin besar kecepatan yang diberikan maka pola goresan yang dihasilkan terlihat lebih sedikit dengan kedalaman keausan yang terlihat lebih dalam. Jika diperhatikan lebih seksama, dapat dilihat bahwa pada foto mikro permukaan kampas dengan kecepatan $100 \mathrm{~km} / \mathrm{jam}$, terjadi pembentukan pola goresan yang lebih sedikit dengan kedalaman keausan yang terlihat jauh lebih dalam jika di banding dengan keausan pada permukaan kampas dengan kecepatan 80 $\mathrm{km} / \mathrm{jam}$ dan $60 \mathrm{~km} / \mathrm{jam}$.

\section{KESIMPULAN}

Berdasarkan hasil pembahasan pengujian keausan dengan variasi kecepatan dapat disumpulkan bahwa:
1. Volume keausan pada masing-masing kecepatan yang dialami oleh kampas rem berbanding lurus dengan lama waktu pengujian. Hal ini menunjukkan bahwa semakin lama waktu pengujian kampas rem maka semakin besar pula volume keausan yang terjadi pada kampas rem tersebut. Hasil volume keausan terbesar dengan waktu 35 menit pada kecepatan $100 \mathrm{~km} / \mathrm{jam}$ sisi kampas A $89,16 \mathrm{~mm}^{3}$ dan volume terkecil pada kecepatan $60 \mathrm{~km} / \mathrm{jam}$ sisi kampas B 30,45 $\mathrm{mm}^{3}$.

2. Hasil koefisien keausan menunjukan bahwa semakin besar kecepatan yang diberikan maka semakin besar pula koefisien keausan. Koefisien terbesar terjadi pada kampas yang menggunakan kecepatan $100 \mathrm{~km} / \mathrm{jam}$ pada sisi kampas A $1,17 \times 10^{-7} \mathrm{~mm}^{3} / \mathrm{N} . \mathrm{mm}$ dan nilai koefisien terkecil ada di kecepatan 60 $\mathrm{km} / \mathrm{jam}$ pada sisi kampas B $7,72 \times 10^{-8}$ $\mathrm{mm}^{3} / \mathrm{N} . \mathrm{mm}$.

3. Diawal pengujian meningkat seiring berjalannya waktu laju keausan yang terjadi cenderung stabil dan mengalami penurunan, hasil laju keausan tertinggi pada waktu pengujian 35 menit dengan kecepatan 100 $\mathrm{km} / \mathrm{jam}$ sisi kampas A $6,24 \times 10^{-8}$ gram/s.mm ${ }^{2}$ dan nilai laju keausan terendah dengan kecepatan $60 \mathrm{~km} / \mathrm{jam}$ pada sisi kampas B 2,62 $\times 10^{-8}$ gram $/ \mathrm{s} . \mathrm{mm}^{2}$.

4. Foto mikro permukaan kampas dari ketiga variasi kecepatan yang diberikan, maka dapat disimpulkan bahwa keausan yang terbentuk dari gesekan dengan metode abrasif. Dapat juga disimpulkan bahwa semakin besar kecepatan yang diberikan maka pola goresan yang dihasilkan terlihat lebih sedikit dengan kedalaman keausan yang terlihat lebih dalam. Jika diperhatikan lebih seksama, dapat dilihat bahwa pada foto mikro permukaan kampas dengan kecepatan $100 \mathrm{~km} / \mathrm{jam}$ terjadi pembentukan pola goresan yang lebih sedikit dengan kedalaman keausan yang terlihat jauh lebih dalam jika di banding dengan keausan pada permukaan kampas dengan kecepatan 80 $\mathrm{km} / \mathrm{jam}$ dan $60 \mathrm{~km} / \mathrm{jam}$.

\section{DAFTAR PUSTAKA}

Archard, J.F., (1953). "Contact and rubbing of flat surfaces”. J. Appl. Phys., 24, 981-988.

Blau., (1997). "Friction Scienceand Technology". From Concepts to Applications, Visit the Taylor \& Francis. 
Jamari., (2006), "Running-In Of Rolling Contacts", phD Thesis, University Of Twente, Enschede, The Nedherlands.

Lancaster J. G. Dowson D. Isaac G. H. and Fisher J., (1997). "The Wear Of UltraHigh Moleculer Weight Polyethylene Sliding On Metallic And Ceramic Counterfaces Reepresentative Of Current Femoral Surface In Join Replacement". Proc. Instn Mech Engrs. Vol 211 Part H.

Sasmito D.P., (2012). Perbandingan Kampas Rem Nonasbes Berserat Fiberglass Dengan Variasi Tembaga 2 Gram, 4 Gram, 6 Gram Dengan Kampas Rem
YamahaTerhadap Keausan, Tugas Akhir. Kekerasan dan Waktu Pengereman, Universitas Muhammadiyah Surakarta, Surakarta.

Stachowiak dan Batchelor., (2001). "Engineering Triblogy", Elsevier Butterworth, Burlington, Amerika Serikat. Sukamto., (2012). "Analisis keausan kampas rem pada sepeda motor", Jurnal Teknik vol. 2 NO. 1, Teknik Mesin Universitas Janabadra, Yogyakarta.

Sutrisno., (1986). "Fisika Dasar Mekanika I", Institut Teknologi Bandung, Bandung 